\title{
Perspectives
}

\section{Reducing social inequalities in obesity: complexity and power relationships}

\section{Anna Matheson}

Massey University, Wellington 6140, New Zealand

Address correspondence to Anna Matheson, E-mail: a.g.matheson@massey.ac.nz

\section{Introduction}

Over the past decade, the public health literature has tended to consider public health interventions as being implemented within a complex environment. ${ }^{1-4}$ This is especially true for obesity, where the evidence is compelling both in terms of the increasing levels of obesity and in inequalities in the burden of obesity. Indeed, the latest commentary on a World Health Organization (WHO) report on childhood obesity argues that it is a 'multi-dimensional' challenge. ${ }^{5}$ More broadly, some have argued that we need to conceptualize a 'fifth wave' of public health where we are now grappling complex issues that require very different methods and solutions to what have been tried in the past. ${ }^{6,7}$

Increasingly more sophisticated frameworks describing the causes of the obesity epidemic are becoming widely accepted such as causal web or socioecological models that depict multiple causal factors and relationships. Among other things, these factors include the relationship between genes, ${ }^{8}$ environment in utero, ${ }^{9}$ individual behaviour, ${ }^{10}$ family behaviours and circumstance, ${ }^{11}$ features of the community, ${ }^{12}$ social networks and capital, ${ }^{13}$ national economic wealth ${ }^{14}$ and human rights, ${ }^{15}$ global $^{16}$ and technological trends ${ }^{17}$ as well as the physical environment such as access to green spaces and proximity to healthy foods. ${ }^{18}$ The temporal dimension of these relationships is also gaining greater credence through life course ${ }^{19}$ and inter-generational perspectives. ${ }^{20}$

Even with these shifts in knowledge, the obesity challenge is still frequently framed as an issue that is complicated, rather than complex. ${ }^{21,22}$ This paper argues that the significance of recognizing obesity as a complex issue is that causal interactions are non-linear and are driven by processes of emergence. Indeed an emergent outcome evident in the social patterning of the obesity epidemic is that social disadvantage is compounded for those also experiencing the greatest burden of obesity.

\section{A crash course in the behaviour of complex systems}

Complexity theory and other theories of complex adaptive systems have been widely utilized within the physical and biological sciences, where the study of interactions is commonplace. The social sciences have flirted with the use of these theories, particularly using dynamic systems modelling to explore the interactions of social variables. To date, however, work in understanding how the underpinning concepts of complexity translate to social systems has been limited. ${ }^{23-25}$ Interestingly, a number of influential social theorists have indirectly created ways of thinking about the problem of emergence- - a central concept within complexity theory. ${ }^{26-28}$ And some have described complexity theory as providing more than merely a reformulation of other social theories which are '... descriptive theories of a particular phenomenon or of the status quo, rather than prescriptive of how to change ... [original emphases]'. ${ }^{26}$

This prescription that complexity theory offers on 'how to change' sees systems as exhibiting behaviour that is independent of the qualitative nature of that system-for example, biological systems where cells interact through chemical signalling or weather systems driven by the interaction of water and temperature. Concepts such as emergence, feedback, self-organization, strange attractors and sensitivity to initial conditions are shared by, and between, biological, physical and social systems. However, it is the interaction between these system behaviours and the specific features of a system that drive the emergence of properties, patterns and structures.

Table 1 illustrates some of these independent behaviours and their implications for intervening to reduce social

Anna Matheson, Senior Lecturer in Public Health 
Table 1 Principles of 'system behaviour' and implications for interventions to reduce obesity

\begin{tabular}{|c|c|c|}
\hline $\begin{array}{l}\text { Principle of system } \\
\text { behaviour }\end{array}$ & What it means for systems & What it means for obesity interventions \\
\hline Strange attractors & $\begin{array}{l}\text { Systems overlap, interrelate and adapt to each } \\
\text { other and have trajectories over time. }\end{array}$ & $\begin{array}{l}\text { Makes explicit the uncertainty involved in achieving social goals in the long } \\
\text { term. Even 'simple' interventions such as healthy food in schools or community } \\
\text { exercise programmes need to also have a long-term system focus where they } \\
\text { are connected to each other and able to adapt to changes in their surrounding } \\
\text { environments. }\end{array}$ \\
\hline Strong emergence & $\begin{array}{l}\text { Highlights how systems relate and adapt to } \\
\text { each other. }\end{array}$ & $\begin{array}{l}\text { Puts an emphasis on relationships between local information and the actions of } \\
\text { social agents from policy, political and economic sectors. }\end{array}$ \\
\hline Self-organization & $\begin{array}{l}\text { Emergent properties result from undirected } \\
\text { actions. }\end{array}$ & $\begin{array}{l}\text { Implies difficulty in controlling social actions and interactions. Problems and } \\
\text { solutions at an individual and small group level are often unknowable and } \\
\text { immeasurable. Suggests formative approaches to intervention at the local level } \\
\text { might be important. }\end{array}$ \\
\hline $\begin{array}{l}\text { Sensitivity to initial } \\
\text { conditions }\end{array}$ & $\begin{array}{l}\text { Sensitivity describes the impact of initial } \\
\text { conditions on a system trajectory. }\end{array}$ & $\begin{array}{l}\text { Sensitivity can result in the reinforcing or compounding of disadvantage for a } \\
\text { population. Suggests an approach to methods of intervention that is locally } \\
\text { intensive but that considers wider system relationships as integral. }\end{array}$ \\
\hline Feedbacks & $\begin{array}{l}\text { Negative feedback reinforces the status quo. } \\
\text { Positive feedback supports change processes. }\end{array}$ & $\begin{array}{l}\text { For communities, there is feedback that is easily identifiable such as the formal } \\
\text { mechanisms of organizations such as evaluations and contracting processes. } \\
\text { But there is also feedback that occurs in less identifiable places such as informal } \\
\text { relationships, the physical environment or information and evidence systems. } \\
\text { Feedback processes can also be transformational for systems-highlighting the } \\
\text { need for community empowerment that considers critical relationships from } \\
\text { the local perspective. }\end{array}$ \\
\hline
\end{tabular}

inequalities in rates of obesity. Non-linearity, for example, is about the processes involved in strong emergence. Strongly emergent properties result from the interactions of large numbers of parts. This does not mean that things have just become more complicated with greater numbers but rather that the rules have changed, meaning that methods and theories of explanation must also change. In systems that exhibit strong emergence, there is a process of 'downward causation' where emergent properties impact on the micro-level interactions creating feedback which again influences the 'whole'. Galea and colleagues ${ }^{1}$ describe how individual exercise patterns are linked to the risk of obesity, but also that obesity is a determinant of individual exercise patterns. This type of emergence contrasts to weak emergence where there is only influence from micro levels to the whole.

The processes involved in emergence encompass concepts such as strange attractors-organizing principles that depict complex, non-linear motions in systems and show their longterm behaviour. ${ }^{23}$ Society can be viewed as diverse 'attractors' that interact with each other and thus change shape. ${ }^{30}$ Self-organization describes the inner workings of a system where parts or components interact in non-linear ways. ${ }^{31}$ Self-organization in social systems ensures that real systems are often unknowable and immeasurable suggesting intervention approaches that are adaptive and locally intensive. ${ }^{24}$

Self-organization resulting in complexity relies on large numbers of interacting lower level parts, will usually exhibit a number of levels of emergent 'wholes' and is made up of positive and negative feedbacks. Negative feedback in social systems can be seen in societal institutions operating in ways that reinforce social norms, limiting the opportunity for adaptation that could shift the circumstance of a community from the status quo. Positive feedback, on the other hand, occurs when a change is reinforced rather than mitigated. For example neighbourhood renewal interventions aim to increase social capital and improve the ability of communities to adapt. ${ }^{32}$ However, this ability to adapt can still be inhibited-and communities 'locked' into their current circumstances-if surrounding systems, and in particular, the policy organizations that fund and evaluate the interventions do not respond appropriately to information that they produce. ${ }^{24,25,33}$

The temporal dimension of complex systems is captured through sensitivity to initial conditions which describes the relationship between initial conditions and the whole system. While short-term system behaviour may be accurately followed, prediction of the longer term behaviour of system 
trajectories becomes impossible. Therefore, even if we know the state of the system very precisely at a particular moment, its future trajectory cannot be predicted. This makes explicit the uncertainty involved in achieving social goals in the long term. ${ }^{34}$ Implications for reducing rates of obesity include avoiding long-term unintended consequences such as increasing inequalities and being cognizant that initial conditions can be, and often are, compounded at the local level—resulting in the compounding of social circumstances. Thus, sensitivity is an important challenge for interventions. ${ }^{4}$

\section{Transforming social systems?}

What does understanding that systems exhibit 'behaviour' say about how we might mitigate the compounding of disadvantage that occurs for some groups and communities? Within social systems what happens to the adaptive ability of communities if systems are shaped by the qualitative features of human subjectivity and agency?

Social systems are hierarchical only in the sense that humans subjectively value some systems over others-exemplified in the perpetuation of social norms and the marginalization of difference. A deeper understanding of the concepts involved in emergence highlight that it is the type of relationship that matters. This suggests that it is more than just relationships between specific people, groups and organizations that are important. The inherent features of the systems these agents are part of also matter especially where information, resources and human capital are destined to flow away from the local. It is this subjectivity that holds the key to transforming our systems. It is not just that disadvantaged communities require empowering. It is more than that. It is rather that the 'local' in general is in need of empowering, with historically little serious attention given by policy and other decision-makers as to what constitutes critical external systems - and particularly how power relationships manifest-from the perspective of the local. It is why community focused and multi-level/dimensional approaches to obesity interventions make a lot of sense, but it is also why attempts at intervention have largely failed to reduce obesity levels, particularly in disadvantaged communities.

'Simple' interventions are still necessary: healthy food in schools, nutrition education for pregnant women, social marketing aimed at increasing exercise levels and the regulation of industries that are influential within local environments. But it is essential to the long-term goal of reducing rates of obesity to ensure that political and private agents are responsive to local information. Of course, it would be easier if divergent interests - such as significant industries — could come on board with the collective conscious goal of reducing obesity. $5,6,35$
However, their collaboration should not be necessary given that we have policy, legal and political processes that can force their hand as well as enabling local communities to better determine their own environments.

As Morrison suggests, theories of complex systems provide a way to understand how to prescribe change-rather than just describing it. ${ }^{26}$ Innovative community interventions grounded in complex systems approaches hold promise for impacting obesity trends, but only as long as they too tackle the more difficult relationships impacting communities. ${ }^{36}$ This paper argues that the transformational potential of complex systems theories lies in their ability to prescribe processes of change through an understanding of system behaviour that advocates a 'whole system' perspective. For interventions to be effective in the long term, it is the qualitative features of real interactions - in particular the manifestation of power relationships — that matter.

\section{Authors' contributions}

The entire paper has been conceived and written by A.M.

\section{Funding}

The main ideas came from my PhD work that was supported by the Health Research Council of New Zealand.

\section{Ethics committee approval}

N/A (although I did receive ethics approval for my PhD research from the University of Otago ethics committee).

\section{References}

1 Galea S, Riddle M, Kaplan G. Causal thinking and complex approaches in epidemiology. Int J Epidemiol 2010;39:97-106.

2 Mehdipanah R, Manzano A, Borrell C et al. Exploring complex causal pathways between urban renewal, health and health inequality using a theory-driven reaist approach. Soc Sci Med 2015;124:266-74.

3 Petticrew M, Anderson L, Elder R et al. Complex interventions and their implications for systematic reviews: a pragmatic approach. J Clin Epidemiol 2013;66(11):1209-14.

4 Rickles D, Hawe P, Shiell A. A simple guide to chaos and complexity. J Epidemiol Community Health 2007;61:933-7.

5 Gluckman P, Nishtar S, Armstrong T. Ending childhood obesity: a multidimensional challenge. Lancet 2015;385:1048-50.

6 Davies S, Winpenny E, Ball S et al. For debate: a new wave of public health improvement. Lancet 2014;384:1889-95.

7 Blackman T, Wistow J, Byrne D. A qualitative comparative analysis of factors associated with trends in narrowing health inequalities in England. Soc Sci Med 2011;72:1965-74. 
8 Wardle J, Carnell S, Haworth CM et al. Evidence for a strong genetic influence on childhood adiposity despite the force of the obesogenic environment. Am J Clin Nutr 2008;87(2):398-404.

9 Ozanne SE. Epigenetics and metabolism in 2014: metabolic programming [mdash] knowns, unknowns and possibilities. Nat Rev Endocrinol 2015;11(2):67-8.

10 Katzmarzyk PT, Barreira TV, Broyles ST et al. Relationship between lifestyle behaviors and obesity in children ages 9-11: results from a 12-country study. Obesity 2015;23(8):1696-702.

11 Frederick CB, Snellman K, Putnam RD. Increasing socioeconomic disparities in adolescent obesity. Proc Natl Acad Sci 2014;111(4): $1338-42$.

12 McCabe MP, Mavoa H, Ricciardelli LA et al. Socio-cultural agents and their impact on body image and body change strategies among adolescents in Fiji, Tonga, Tongans in New Zealand and Australia. Obes Rev 2011;12(Suppl. 2):61-7.

13 Putland C, Baum F, Ziersch A et al. Enabling pathways to health equity: developing a framework for implementing social capital in practice. BMC Public Health 2013;13(517): doi:10.1186/1471-245813-517.

14 Popkin BM, Slining MM. New dynamics in global obesity facing lowand middle-income countries. Obes Rev 2013;14(S2):11-20.

15 Kumanyika SK. A question of competing rights, priorities, and principles: a postscript to the Robert Wood Johnson Foundation Symposium on the Ethics of Childhood Obesity Policy. Prev Chronic Dis 2011;8(5):1-4.

16 Popkin BM. Nutrition transition and the global diabetes epidemic. Curr Diab Rep 2015;15(9):1-8.

17 Gilmore LA, Duhé AF, Frost EA et al. The technology boom a new era in obesity management. I Diabetes Sci Technol 2014;8(3): 596-608

18 Lake A, Townshend T. Obesogenic environments: exploring the built and food environments. J R Soc Promot Health 2006;126(6):262-7.

19 Masters RK, Powers DA, Link BG. Obesity and US mortality risk over the adult life course. Am J Epidemiol 2013;177(5):431-42.

20 Adamo KB, Ferraro ZM, Brett KE. Can we modify the intrauterine environment to halt the intergenerational cycle of obesity? Int J Environ Res Public Health 2012;9(4):1263-307.
21 Finegood D, Merth T, Rutter H. Implications of the foresight obesity system map for solutions to childhood obesity. Obesity 2010;18(1):S13-5.

22 Roberto C, Swinburn B, Hawkes C et al. Patchy progress on obesity prevention: emerging examples, entrenched barriers, and new thinking. Lancet 2015;385(9985):2400-9.

23 Byrne D. Complexity Theory and the Social Sciences. London: Routlege, 1998.

24 Byrne D. Social Exclusion. Berkshire: Open University Press, 2005.

25 Matheson A, Dew K, Cumming J. Complexity, evaluation and the effectiveness of community-based interventions to reduce health inequalities. Health Promot J Austr 2009;20(3):221-6.

26 Morrison K. Structuration theory, habitus and complexity theory: elective affinities or old wine in new bottles? Br J Sociol Educ 2005;26(3): $311-26$.

27 Sawyer K. Durkheim's dilemma: toward a sociology of emergence. Soc Theory 2002;20(2):227-47.

28 Fuchs C. Some implications of Pierre Bourdieu's works for a theory of social self-organisation. Eur J Soc Theory 2003;6(4):387-408.

29 Goldstein J. Emergence as a construct: history and issues. Emergence 1999;11:49-72.

30 Gilstrap D. Strange attractors and human interaction: leading complex organizations through the use of metaphors. Complicity 2005;2(1):55-69.

31 Arshinov V, Fuchs C. Causality, Emergence, Self-Organisation. Moscow: NIA-Priroda, 2003.

32 Durie R, Wyatt K. New communities, new relations: the impact of community organization on health outcomes. Soc Sci Med 2007;65: $1928-41$

33 Judge K, Bauld L. Learning from policy failure? Health Action Zones in England. Eur J Public Health 2006;16(4):341-4.

34 Osberg D, Biesta G. Beyond presence: epistemological and pedagogical implications of 'strong' emergence. Interchange 2007;38(1):31 - 51.

35 Thow AM, Snowdon W, Schultz JT et al. The role of policy in improving diets: experiences from the pacific obesity prevention in communities food policy project. Obes Rev 2011;12(Suppl. 2):68-74.

36 Foulkes C. Systems interventions to halt and reverse rising trends in obesity what theories, methodologies and methods actually aid practice: Cases from Healthy Together Geelong. Obes Res Clin Pract 2014;8:33-4. 